\title{
Representações LGBTQIA+ e estudos culturais: invisibilidades da diversidade de gênero em audiovisuais publicitários de moda
}

\author{
LGBTQIA+ representations and cultural studies: invisibility of gender \\ diversity in fashionable audiovisuals
}

Representaciones LGBTQIA+ y estudios culturales: invisibilidades de la
diversidad de género en audiovisuales publicitarios de moda

Luciomar de Carvalho ${ }^{1, a}$

dgluciomarc@gmail.com | https://orcid.org/oooo-0003-4981-8412

Flavi Ferreira Lisboa Filho ${ }^{1, b}$

flavilisboa@gmail.com | http://orcid.org/o000-0003-4307-9401

\footnotetext{
${ }^{1}$ Universidade Federal de Santa Maria, Programa de Pós-graduação em Comunicação. Santa Maria, RS, Brasil.

a Mestrado em Desenvolvimento pela Universidade Regional do Noroeste do Estado do Rio Grande do Sul.

${ }^{\text {b }}$ Doutorado em Ciências da Comunicação pela Universidade do Vale do Rio dos Sinos.
}

\section{Resumo}

A moda, não raras vezes, é utilizada como marca de distinção social e de apagamentos de gêneros. Mesmo nos dias atuais, sua produção hegemônica distingue os gêneros feminino e masculino e deixa os demais sem representatividade. Por outro lado, a crítica a um modelo de produção publicitário, que robustece os padrões hegemônicos dos binarismos compulsórios entre sexo e gênero, tem sido efetivada por um movimento acanhado e ainda recente que clama por novos modelos de representação. Por meio dos estudos culturais, este ensaio teórico busca refletir sobre as representações LGBTQIA+ nas publicidades de moda, salientando a importância das diversidades de gênero estarem representadas, de forma não estereotipada, dando-lhes visibilidade, evitando seu silenciamento e apagamento.

Palavras-chave: Estudos culturais; Representação; LGBTQIA+; Moda; Publicidade. 


\begin{abstract}
Fashion is often used as a sign of social distinction and erasure of genres. Nowadays its hegemonic production still distinguishes female and male gender but the others have no representation in it. On the other hand, the criticism about a model of advertising production, which strengthens the hegemonic patterns of compulsory binarisms between sex and gender, has been effected by means of a few expressive and still recent movement that calls for new models of representation. This theoretical essay seeks through cultural studies to reflect on LGBTQIA+ representations in fashion advertising, stressing the importance of gender diversity to be represented in a non-stereotyped way, giving them visibility, avoiding to silence them and their erasure.
\end{abstract}

Keywords: Cultural studies; Representation; LGBTQIA+; Fashion; Publicity.

\title{
Resumen
}

La moda se usa a menudo como una marca de distinción social y borradura de géneros. Incluso hoy, su producción hegemónica distingue el género femenino y el masculino y deja otros géneros sin representatividad. Por otro lado, la crítica a un modelo de producción publicitario, que fortalece los patrones hegemónicos de binarismos obligatorios entre el sexo y el género, tiene sido efectuada por medio de un movimiento tímido y aún reciente que exige nuevos modelos de representación. A través de estudios culturales, este ensayo teórico busca reflexionar sobre las representaciones LGBTQIA+ en las publicidades de moda, enfatizando la importancia de que las diversidades de género estén representadas de manera no estereotipada, dándoles visibilidad, evitando su silenciamiento y borradura.

Palabras clave: Estudios culturales; Representación; LGBTQIA+; Moda; Publicidad.

Este artigo faz parte do dossiê $\mathbf{4 0}$ anos do movimento LGBT: visibilidades e representações.

Contribuição dos autores:

Concepção e desenho do estudo: Luciomar de Carvalho e Flavi Ferreira Lisboa Filho.

Aquisição, análise ou interpretação dos dados: Luciomar de Carvalho e Flavi Ferreira Lisboa Filho.

Redação do manuscrito: Luciomar de Carvalho e Flavi Ferreira Lisboa Filho.

Revisão crítica do conteúdo intelectual: Luciomar de Carvalho e Flavi Ferreira Lisboa Filho.

Declaração de conflito de interesses: não há.

Fontes de financiamento: Universidade Federal de Santa Maria e Coordenação de Aperfeiçoamento de Pessoal de Nível Superior.

Considerações éticas: não há.

Agradecimentos/Contribuições adicionais: não há.

Histórico do artigo: submetido: 02 fev. 2019 | aceito: 14 ago. 2019 | publicado: 12 set. 2019.

Apresentação anterior: não há.

Licença CC BY-NC atribuição não comercial. Com essa licença é permitido acessar, baixar (download), copiar, imprimir, compartilhar, reutilizar e distribuir os artigos, desde que para uso não comercial e com a citação da fonte, conferindo os devidos créditos de autoria e menção à Reciis. Nesses casos, nenhuma permissão é necessária por parte dos autores ou dos editores. 


\section{Introdução}

As diferenças entre gênero e a construção social das percepções sexuais são históricas, e a necessidade de romper com o binarismo feminino/masculino, de modo a reconhecer a diversidade existente no interior de cada um deles merece destaque ${ }^{1}$. Com base nos estudos culturais, este ensaio teórico reflete sobre as representações Lésbicas, Gays, Bi, Transsexuais, Queer, Intersexo, Assexuais/Agênero e mais (LGBTQIA+) tendo, como exemplos, duas publicidades de moda (Renner e Riachuelo) e salientando a importância de sua presença e visibilidade, especialmente, na mídia.

Movimentos de contracultura são ferramentas de alteração social com o objetivo de "denunciar e tentar reverter as condições de marginalização e exclusão impostas a amplos estratos sociais [...]”’. O contrahegemônico é, portanto, como uma tensão, um teste de forças históricas entre massas de grupos sociais, que pode ser transformada.

Por sua vez, a moda, um campo que abrange e reúne inúmeras informações foi e ainda é palco de distinção social e de gênero em uma sociedade 3 . Como exemplo, podemos citar as seções das lojas de departamento, cujos produtos são separados pela binariedade de gênero (masculino e feminino) e isso reflete os limites impostos em relação a uma pretensa diversidade de gênero. Em outra via, um dos elementos presentes no nosso cotidiano e capaz de atingir as massas e auxiliar na reversão da binariedade hegemônica de gênero é a publicidade audiovisual.

Assim, entendemos que se torna imprescindível analisar o papel das publicidades de moda na construção de produtos audiovisuais capazes de contribuir na luta por mudanças contra-hegemônicas, criando extrusões em quadros de dominação.

\section{Contextualizações acerca dos estudos culturais e estudos de gênero}

Para compreender as representações das identidades de gênero que permeiam nossa sociedade, é necessário, primeiramente, compreender o conceito de gênero. Em um movimento de expansão das problemáticas de reconhecimento individual na sociedade contemporânea, o termo foi elaborado em uma dinâmica particular de problematizações, buscando complexificar ainda mais as diferenças entre os sexos como diferenças socialmente construídas.

O entendimento contemporâneo sobre a história das relações de gênero é marcado pelo nascimento das diferenças entre homens e mulheres a partir do reconhecimento de certo valor econômico como norteador da organização social. Foi através da escassez da coleta de pequenos animais para caçar que fez com que o homem passasse a ter destaque na sociedade, bem como na guerra por mais territórios e pela força física para caçar grandes animais ${ }^{4}$. Esse marco fundamenta "a grande derrota do sexo feminino" 5 ; afinal, a força física e a esfera econômica passam a guiar o mundo, fato que origina um sistema patriarcal, com subjugação do feminino ao masculino, valorizando este em detrimento daquele, para quem se estabelece papéis sociais permitidos e, os estudos culturais, de certo modo, vão trazer esse tema. A perspectiva dos estudos culturais surgida no final dos anos 1950, período pós-guerra em que o mundo passava por uma crise econômica e política muito grande, adotava um tom mais político, tentando compreender a cultura por meio dos movimentos sociais da época, sob o ponto de vista teórico, buscando construir um novo campo de estudos de caráter interdisciplinar ${ }^{6}$.

Os estudos culturais foram entendidos como um ambiente de alianças, para o qual a perspectiva marxista contribuiu, questionando limites entre alta e baixa cultura, pluralismos e hegemonias; assim, o feminismo, a política negra, o movimento gay, os estudos chicanos, os grupos crescentes de estudos pós-coloniais, bem como outros grupos mais tradicionais, como fãs de diferentes culturas e culturas populares, são bem-vindos e entendidos nesse meio ${ }^{7}$.

A socialização é uma totalização pontual, na qual os planos de raça, gênero, etnia e sexualidade se cruzam para formar uma estrutura operativa em que nenhum destes ou outros grupos têm uma cultura por 
conta própria. A cultura é algo que um grupo compreende quando entra em contato com outro, ou seja, uma cultura é um conjunto de marcas que um grupo percebe no outro7.

É nessa perspectiva que o campo de estudo se torna uma crítica focada no questionamento do estabelecimento de hierarquias, nas práticas culturais, ajustadas a partir de oposições, das binariedades, tendo entre suas finalidades a ideia de revelar os discursos marginais ou daqueles que não têm voz ${ }^{6}$, de tentar combater as desigualdades, contra as quais o movimento feminista foi um dos precursores na luta.

O termo 'feminismo' surgiu com o objetivo de problematizar as diferenças entre homens, mulheres e tratar a desigualdade de gênero como uma construção social. Assim, a partir dos anos 1970, a noção de gênero é desenvolvida de forma a complexificar o debate sobre as diferenças entre mulheres e homens, retirando do biológico o primado para as explicações sobre as relações sociais. Durante muito tempo, sexo foi considerado o mesmo que gênero, e as teorias feministas desconstruíram isto afirmando que "aquela formulação patriarcal cumpriu a função de naturalizar assimetrias, estabelecendo uma prática social que serviu aos interesses do homem"8. Portanto, diferentemente de sexo - dado biológico que não é suficiente para determinar o comportamento distinto do feminino ou do masculino - o termo gênero "é um produto construído no social, assimilado, figurado, instituído, transmitido de geração a geração”. Ou seja, o gênero está enraizado em cada cultura e o podemos perceber no fato de que desde pequenos somos 'acostumados' a fazer distinções entre o feminino e o masculino, a exemplo de delimitações rasteiras como as de que roupas cor-de-rosa e bonecas são apenas para meninas, assim como a cor azul e os carrinhos são para meninos.

Dessa forma, podemos dizer que enquanto sexo está intrinsecamente ligado a uma implicação biológica, que é insuficiente para determinar comportamentos masculinos ou femininos, gênero é social e cultural, além de ser construído, assimilado, figurado e instituído socialmente ${ }^{9}$. Esta definição implica relacionarmos o gênero como algo enraizado culturalmente, que vai ao encontro da proposta dessa abordagem; afinal, gênero está para além do feminino e do masculino, abarcando uma diversidade que pode existir individualmente.

Assim busca-se destacar um breve relato sobre o surgimento do movimento LGBTQIA+ e sua importância para a visibilidade da diversidade de gêneros. A primeira organização gay surge nos Estados Unidos no ano de 1924 e se tratava de uma experiência bastante embrionária. Na década de 1960, a segunda onda do feminismo passou a denunciar com mais vigor as disparidades enfrentadas pelas mulheres na vida particular, no trabalho e nos espaços públicos, sendo este período também expressivo para lésbicas, gays, bissexuais e pessoas trans. O ano de 1969 aponta o surgimento dos movimentos representantes das sexualidades não hegemônicas como um conjunto político, em processo de organização e reclamação de direitos $^{10}$. "Os anos subsequentes registraram o surgimento, em diversas cidades norte-americanas, de organizações voltadas aos direitos dos homossexuais. Persistia, entretanto, a perseguição da polícia, a cobrança de propina e a exigência de favores sexuais nas batidas em bares frequentados por gays e lésbicas" ${ }^{\prime 10}$.

O movimento homossexual, de modo mais organizado, surge no Brasil na segunda metade da década de 1970, período em que ainda existia muita confusão entre sexo, gênero e orientação sexual, dificultando entender o que era a homossexualidade. Os anos 2000 trouxeram uma maior pluralidade nos debates sobre o movimento LGBTQIA+, com o aumento de pesquisas acadêmicas e a propagação de paradas da diversidade por todo o país ${ }^{10}$. O movimento LGBTQIA+ passou, a partir desse período, a ser tratado com mais naturalidade nas produções culturais, como peças de teatro, filmes, telenovelas, publicidades. Esses avanços ocorreram, mas ainda é grande a pressão dos grupos heteronormativos em reduzir ou fragilizar as pautas LGBTQIA+.

Portanto, "não há razão para supor que os gêneros devam permanecer no número de dois" e, assim, os debates sobre gênero devem permear a desestabilização das identidades hegemônicas a partir de discursos e práticas subversivas às ordens vigentes. 


\section{Olhares sobre moda e cultura}

Na pré-história e na Antiguidade oriental, surge a moda, quando o ser humano passa a utilizar folhas vegetais e, em seguida, peles de animais para cobrir o corpo $^{11}$.

A importância do tema moda para o entendimento da cultura brasileira, contudo, só irá, de fato, ser estabilizado, a partir dos anos 1980, com as inovações que o fenômeno moda passa a ter. "Após a Segunda Guerra Mundial e os movimentos culturais dos anos 1960, com a emergência do período pós-industrial do capitalismo, o mundo da moda passou por grandes transformações, voltando a ocupar um lugar de destaque entre pesquisadores”3.

As mudanças culturais que derivaram desse novo momento histórico, no qual os jovens passaram a ser um dos atores principais, produziram novos desenhos de ver o mundo. Essa virada cultural passou a ser mais decisiva a partir dos anos 1960, quando o impacto das ideias que se gestaram nos anos 1950, do rock ao existencialismo, se ampliam em movimentos não apenas de cunho político, mas, especialmente, cultural. "O que realmente mudou o mundo foi a revolução cultural da década de 1960. O ano de 1968 pode ter sido menos um ponto decisivo na história do século XX do que o ano de 1965, que não teve qualquer significação política, mas foi o ano em que pela primeira vez a indústria francesa de roupas produziu mais calças femininas do que saias” ${ }^{2}$.

Os períodos de mudanças culturais marcantes mencionados foram fundamentais, muito embora, a moda intervenha constantemente na vida das pessoas, seja nos seus relacionamentos, nas suas atitudes, suas personalidades ou nas suas tradições cotidianas.

Uma das fontes da moda prêt-à-porter, que traduzido quer dizer pronto para vestir, é um segmento que tem preço intermediário entre o da alta costura e da fast-fashion, e uma possibilidade de reconhecer que o indivíduo expresse sua personalidade e individualidade por meio da moda. Dessa forma, a moda atua como agente da liberdade de escolha, não só com respeito à vestimenta, mas também do estilo de vida, das atitudes e dos comportamentos ${ }^{13}$.

À medida que as tecnologias avançam, atualizam-se os artefatos da moda e essas informações são repassadas com mais rapidez ainda pela mídia. "A mídia é um dos maiores disseminadores da moda, independente do meio como é transmitido, no entanto"11.

As mídias trouxeram numerosas ações de transformação nas estruturas de construção identitária. A televisão participou dessas expressivas mudanças e obrou procedimentos de aculturação que geraram novos modelos de comportamento e concepções de identidade. Neste sentido, moda representa considerável relevância na sociabilidade dos sujeitos nas interações cotidianas, atribuindo identidades e papéis sociais aos indivíduos. Os aparatos ideológicos usados pelas mídias, que articulam e difundem tendências de moda, são elementos fundamentais na percepção que os indivíduos têm desses produtos e precisam ser investigados com propriedade, a fim de esclarecer as estratégias de manipulação que elas adotam, com o intuito de defender a livre expressão identitária e o esclarecimento do indivíduo ${ }^{14}$.

Uma das mais evidentes e representativas áreas da teoria contemporânea da cultura popular é a moda. A moda como prática cultural, tem produzido algumas análises expressivas dos efeitos da contemporaneidade na mais íntima, geral e difundida dimensão da vida sociocultural ${ }^{13}$.

Desse modo, a cultura acaba por ser um campo de batalha e será nesse campo de negociações de sentidos que a moda se constitui como veículo de difusão da diversidade de identidades, de uma maior visibilidade da população LGBTQIA+, e a publicidade reforça essa difusão, reforça a legitimação do movimento. 


\section{Representações LGBTQIA+ no audiovisual publicitário}

Com o passar dos anos, as distintas identidades de gênero são representadas pela mídia de modo variado. Entretanto, é necessário compreender o significado do termo representação social. As representações sociais são fenômenos complexos e ativos. "É uma forma de conhecimento, socialmente elaborado e compartilhado, que tem um objetivo prático, e concorre para a construção de uma realidade comum a um conjunto social”"15.

A representação é uma espécie de identificação, que busca referências em ideias, imagens, músicas etc. E ainda, "a ênfase na representação e o papel-chave da cultura na produção dos significados que permeiam todas as relações sociais levam, assim, uma preocupação com a identificação"16.

Dessa maneira, a mídia, como principal difusor de ideias, fez com que as representações sociais, sejam elas étnicas, sexuais ou de classe, se tornassem mais fortes. Assim, os meios de comunicação "são responsáveis pela produção dos sentidos que circulam na sociedade" ${ }^{{ }_{17}}$, transmitindo valores e cultura. Essa produção de sentidos está intrinsecamente relacionada, principalmente, à televisão, especialmente no caso brasileiro, por ser o meio de comunicação com maior nível de abrangência, atingindo milhões de lares diariamente, tornando-se um importante difusor no que diz respeito às representações sociais.

O conceito de representação, por vezes, aciona o de identidade, que corresponde ao conjunto de características que servem como reconhecimento de determinado grupo social. As identidades contemporâneas não são fixas e imutáveis e, por meio do fenômeno da globalização, as distâncias foram encurtadas, aproximando outras culturas, bem como trazendo mudanças nas formas de constituição da identidade do sujeito. As mudanças na identidade podem ser vistas na configuração dos papéis sociais aquilo que desempenhamos nos mais distintos momentos de nosso cotidiano, que organizam funções e também convencionam ideias e pensamentos aceitos ou não em determinado grupo ${ }^{18}$. Assim, somos capazes de observar sujeitos que se reconhecem, sistematicamente, em diversos papéis sociais: por exemplo, há a mulher do privado, a mãe que convive com as demandas da mulher pública, o homem que cuida da casa, a mulher transgênero líder política etc. Além disso, as configurações familiares, antes amplamente reguladas por valores morais conectados ao determinismo biológico, hoje se multiplicam.

Assim, a identidade pode ser considerada um quebra-cabeça, "ao qual faltam muitas peças (e jamais se saberá quantas)" ${ }^{19}$. É nesse sentido que entra em questão a representação da identidade de gênero em produtos audiovisuais. Por esse viés, a mídia trabalha com representações coletivas, fazendo o uso de estereótipos, no que diz respeito aos grupos sociais minoritários, como sua principal estratégia discursiva, já que estes conseguem ser facilmente reconhecíveis. Por isso, somos acostumados a ver em programas de televisão, por exemplo, lésbicas que se vestem como homens, gays superafeminados e com trejeitos, como se fosse a única forma de representação desses grupos. Ou seja, a mídia reforça apenas um tipo de identidade de gênero e isso faz com que os telespectadores as aceitem como únicas, passando a figurar como a imagem real daquele indivíduo ou grupo, tornando-se parte do senso comum.

No espaço audiovisual, as produções publicitárias têm contribuído e muito para a estereotipificação sexual das sociedades. A análise das propagandas não permite determinar sua recepção, as maneiras como foram digeridas ou recriadas pelo público, mas nos aproxima de elementos que lhes foram oferecidos pelo discurso publicitário e que compunham o conjunto de representações que circulavam no espaço urbano ${ }^{20}$. A publicidade não inventa coisas, seu discurso, suas representações estão sempre relacionados com o conhecimento que circula na sociedade, mas, que por outro lado, as pessoas se valem de sua percepção para recriá-la ${ }^{21}$. É preciso que se ofereça uma maior pluralidade e diversidade nas produções, principalmente as audiovisuais. "A liberdade de fruição dos diferentes níveis culturais como possibilidade aberta a todos (mas não escolhida por todos) depende de duas forças: Estados que intervenham equilibrando o mercado, cuja estética denuncia seu compromisso com o lucro; e uma crítica cultural que possa livrar-se do duplo isolamento da celebração neopopulista do existente e dos preconceitos elitistas que solapam a possibilidade de articular uma perspectiva democrática”22. 
Cabe, então, às produções publicitárias, nesse caso às audiovisuais de moda, evitarem padrões hegemônicos que ainda são impostos e expostos. Neste artigo, refletimos, por meio dos estudos culturais, sobre a importância da população LGBTQIA+ estar representada nas publicidades de moda de forma não estereotipada, dando-lhes visibilidade, evitando seu silenciamento e apagamento.

\section{Audiovisuais publicitários de moda e os padrões hegemônicos}

A noção de hegemonia indica processos de dominação e submissão de significados, valores e crenças de uma classe sob a outra, de um sujeito sob o outro.

A hegemonia é o conjunto de ações e expectativas sobre o conjunto da vida. "É um sistema vivido de significados e valores - constitutivo e constituidor - que, ao serem experimentados como práticas parecem confirmar-se reciprocamente. Constitui assim um senso da realidade para a maioria das pessoas na sociedade, um senso de realidade absoluta, porque experimentada, e além da qual é muito difícil para maioria das áreas de sua vida. Em outras palavras, é no sentido mais forte uma cultura, mas uma cultura que tem de ser considerada como o domínio e subordinação vividos de determinadas classes"²3.

A hegemonia é complexa e está sempre em redefinição e atualização, não apenas no campo econômico de classes, mas também nas instâncias culturais e nas relações sociais. Entretanto, ainda que a concepção hegemônica seja um processo extenso e represente disputas de poder, essas particularidades não determinam que inexista uma resistência, efetivada por manifestações culturais adversas a esse processo ${ }^{17}$. "A hegemonia cultural nunca é uma questão de vitória ou dominação pura (não é isso que o termo significa); nunca é um jogo cultural de perde-ganha; sempre tem a ver com mudança no equilíbrio de poder nas relações da cultura; trata-se de mudar as disposições e configurações do poder cultural e não se retirar dele" ${ }^{{ }_{17}}$.

Esse equilíbrio de poder e de mudanças de posições tendem a surgir por intermédio de movimentos definidos como contra-hegemônicos, quebuscam alteraro cenário de dominação sustentado pelo pensamento hegemônico, impulsionados pela diversidade de padrões como religião, raça e etnia, sexualidade, gênero etc. O contra-hegemônico é, portanto, como uma tensão, uma medição de forças históricas entre blocos de grupos sociais, que podem ser reelaboradas, alteradas e modificadas.

Portanto, o papel da publicidade e da mídia como um todo é de extrema importância na constituição de instrumentos essenciais para transformações contra-hegemônicas, criando rupturas em quadros de dominação. "Na essência, o discurso midiático se propõe a determinar a interpretação dos fatos por intermédio de signos fixos e constantes que tentam proteger de contradições aquilo que está dado e aparece como representação do real, como verdade. Tal discurso interfere preponderantemente na cartografia do mundo coletivo, propondo um conjunto de linhas argumentativas sobre a realidade, aceitas ou consideradas por amplos setores da sociedade" ${ }^{24}$.

Tratando-se de publicidade de moda, esse meio frequentemente reforça valores hegemônicos e está inteiramente integrado à determinação de concepções imaginárias e reprodução de ideias e estereótipos que operam como instrumento de organização social por serem, de acordo com a história, impregnados de julgamentos e pressupostos de comportamento de definidos grupos e pessoas. Em campanhas publicitárias do ramo da moda, o hegemônico é também recortado por pontos étnicos, de classe e de sexo e é relacionado, sobretudo, à hegemonia étnico-racial branca, do sexo masculino e de orientação heterossexual, que desfrutam de maior visibilidade e poder de representação.

Muitas vezes, a publicidade subverte padrões já estabelecidos, não como forma de contestação e sim como um modo de chamar atenção para o produto que está à venda. Desse modo, encontramos em algumas publicidades audiovisuais de moda casais homossexuais, negras e negros e/ou pessoas com padrões de beleza que fogem da estética dominante, trazendo a diversidade à tona, mas, ainda assim, esses casos são poucos e constituem muito mais uma exposição de discursos que já circundam a sociedade, como a homossexualidade, por exemplo, do que uma determinação de tornar visíveis questões entendidas 
como tabus sociais, dando voz a grupos minoritários. Quando a publicidade de moda se utiliza da homossexualidade para vender algum produto ou serviço é porque de alguma forma esse discurso já está circulando na sociedade. Entretanto, é preciso atentar que, ao apresentar esses sujeitos, a publicidade os está ao mesmo tempo produzindo e/ou estereotipando.

Como exemplo, citamos a publicidade da marca de moda das Lojas Renner e Riachuelo. Essas surgiram como exemplos que reforçam este ensaio teórico, quando ao lançar na internet, mais precisamente no YouTube, as palavras-chave 'publicidade, moda, diversidade', as publicidades que primeiramente surgiram e chamaram a atenção, ao não representarem de forma concisa a diversidade de gênero, foram as destacadas. Elas, supostamente, propõem desde as nominações a diversidade, a aceitação para além da binariedade imposta pela sociedade como padrão, mas, ao serem visualizadas, não representam a diversidade de gênero em seus contextos. Para este ensaio não aprofundamos uma análise textual dessas publicidades, e, sim, apresentamos estas como arquétipos reforçadores da teoria destacada nesse contexto.

No caso da publicidade Renner a 'diversidade' está mencionada na chamada do YouTube: "Na infância, aprendemos que $1+1=2$. Mas depois a vida vai nos ensinando a aplicar essa fórmula simples de outros jeitos..." ${ }^{25}$. Esse anúncio refere-se ao dia dos namorados de 2018, e em sua produção há a exposição de uma diversidade de casais, representando os namorados, mas ela acaba construindo em seu enredo, um tipo de 'identidade' adequado a cada casal/gênero/sexo, ao mesmo tempo que tenta preservar essas 'identidades'. O beijo, o toque, o carinho fica representado somente por casais heterossexuais. A representação de casais homoafetivos somente ocorre na troca de olhares, por milésimos de segundos. Na Figura 01, estão destacados esses momentos pontuais em que a marca tenta representar a diversidade de gênero.

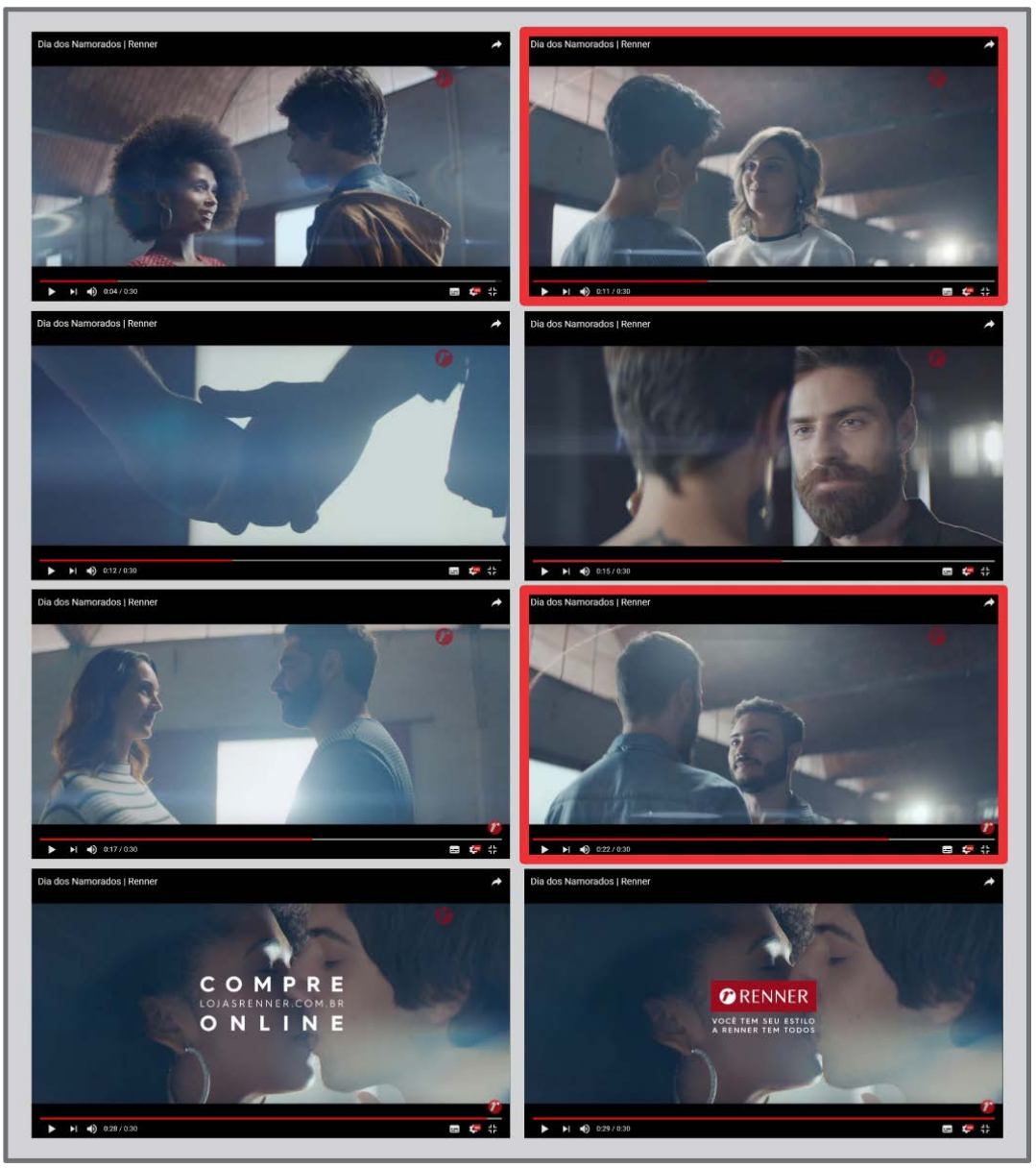

Figura 1 - Quadros do audiovisual publicitário das Lojas Renner. Fonte: https://www.youtube.com/watch?v=wxEwmSyxAEw 
Já a marca Riachuelo traz em sua publicidade de final do ano de 2017 a máxima "seja você seja feliz ao lado de quem você ama”26. Nela, há várias exposições de famílias, casais são representados na peça, mas fica evidente que os casais dessa publicidade são heterossexuais, pois os casais homossexuais foram excluídos. Eles estão silenciados, invisibilizados no contexto do material audiovisual. Representa-se uma família tradicional da binariedade hegemônica homem/mulher/cis, ou seja, a felicidade hoje, como a marca propõe na publicidade, somente se dá ao adentrar na lógica hegemônica de nossa sociedade. A publicidade da marca Renner, comparada com a da Riachuelo subverte padrões já estabelecidos, mas não como forma de contestação e sim como um modo de chamar atenção para o produto que está à venda. Já a marca Riachuelo apaga a população LGBTQIA+ de seu vídeo.

\section{Considerações finais}

Desde o seu surgimento, o movimento LGBTQIA+ passou por inúmeras transformações de luta pelo reconhecimento da diversidade sexual e de gênero. Os empenhos realizados para que a população LGBTQIA+ desfrute de direitos íntegros nas últimas décadas conquistaram resultados positivos, mas conquistas atuais, como se é percebido na mídia, no caso, nos audiovisuais publicitários de moda, vêm acompanhadas do acréscimo de algumas intolerâncias e invisibilidades.

As produções audiovisuais publicitárias da atualidade, em sua maior parte, ainda que em diversos aspectos se ajustem a um modelo hegemônico que somente beneficia o mercado, podem contribuir para abrir um importante debate sobre questões de gênero e diversidade. As produções publicitárias de moda que não representam as diversidades de gênero as invisibilizam, silenciam e menosprezam, reforçando o preconceito no âmbito discursivo e social.

Assim, o papel dos audiovisuais publicitários na ressignificação das representações é essencial enquanto mediador da sociedade contemporânea no que tangeàs alterações das representações da população LGBTQIA+, desde que conectado à luta histórica de sujeitos que buscam visibilidade, respeito e inserção social. Aqui, não estamos falando da simples representação, mas sim de representatividade, no seu sentido político, no sentido de espaço de fala, pois, quando entendemos que o lugar social que certos grupos ocupam restringem suas oportunidades, percebemos a dimensão da importância que a publicidade audiovisual carrega. Esse espaço se torna um meio de visibilidade de assuntos e identidades comumente invisibilizados em nossa sociedade.

\section{Referências}

1. Farah MFS. Gênero e políticas públicas. Estudos feministas. 2004;12(1):47-71.

2. Moraes $D$, organizador. Mutações do visível: da comunicação de massa à comunicação em rede. Rio de Janeiro: Pão e Rosas; 2010.

3. Crane D A moda e seu papel social: classe, gênero e identidades nas roupas. São Paulo: Editora Senac São Paulo; 2006.

4. Saffioti HIB. Novas perspectivas metodológicas de investigação das relações de gênero. In: Moraes Silva MA, organizadora. Mulher em seis tempos. Araraquara: Faculdade de Ciências e Letras, Unesp; 1991.

5. Beauvoir S. O segundo sexo. Fatos e Mitos. São Paulo: Difusão Europeia do Livro; 1970.

6. Escosteguy AC. Cartografia dos estudos culturais: uma versão latino-americana. Belo Horizonte: Autêntica; 2001.

7. Jameson F. Los estudios culturales. Buenos Aires: Godot; 2016.

8. Santos SRP. Representação do feminino em uma escritura desautorizada: Celeste, de Maria Benedita Câmara Bormann e o Perdão, de Andradina América Andrade de Oliveira [tese na Internet]. Porto Alegre: Universidade Federal do Rio Grande do Sul, 2007 [citado em 2019 ago 21]. Disponível em: http://www. lume.ufrgs. br/bitstream/handle/10183/12756/000632521.pdf?sequence=1. 
9. $\quad$ Butler J. Problemas de gênero: feminismo e subversão da identidade. Rio de Janeiro: Editora Civilização Brasileira; 2015.

10. Sales RG. Políticas de respeito à diversidade sexual no ambiente de trabalho: análise das percepções sobre o papel da comunicação em organizações participantes do Fórum de Empresas e Direitos LGBT [Dissertação]. São Paulo: Universidade de São Paulo; 2017.

11. Lopes IG, Marques DP, Lisboa Filho FF. Moda e mídia: representação de identidades a partir do consumo. In: Anais do $11^{\circ}$ Congresso de Ciências da Comunicação na Região Sul. 2010. Novo Hamburgo, RS: Sociedade Brasileira de Estudos Interdisciplinares da Comunicação - Intercom; 2010.

12. Hobsbawn E. Tempos interessantes: uma vida no século XX. São Paulo: Companhia das Letras; 2002.

13. Lipovetsky G. O império do efêmero: a moda e seu destino nas sociedades modernas. São Paulo: Companhia das Letras; 2009.

14. Morais MM. Moda \& Mídia: aspectos culturais, identitários e sociais. Intercom, Sociedade Brasileira de Estudos Interdisciplinares da Comunicação. In: Anais do $29^{\circ}$ Congresso Brasileiro de Ciências da Comunicação. 2006. Brasilia: UnB; 2006.

15. Jodelet $D$. Représentations sociales: un domaine en expansion. In: Jodelet $D$, editor. Representações sociais: um domínio em expansão. Mazzotti TB, tradutor. Alves-Mazzotti AJ, revisão técnica. Rio de Janeiro: UFRJ; 1993. p. 31-61.

16. Woodward K. Identidade e diferença: uma introdução teórica e conceitual. In: Silva TT, organizador. Identidade e diferença: a perspectiva dos Estudos Culturais. Petrópolis, RJ: Vozes; 2000.

17. Morigi VJ. Teoria social, comunicação: representações sociais, produção de sentidos e construção dos imaginários midiáticos. E-Compós. 2004;(1):1-14.

18. Hall S. A identidade cultural na pós-modernidade. Rio de Janeiro: DP\&A; 2003.

19. Bauman Z. Identidade. Rio de Janeiro: Jorge Zahar; 2005.

20. Trotta T, Carvalho MG. Representações sociossemióticas na mídia. In: Schwartz J. et al., organizadores. Discutindo as representações de gênero na literatura, no teatro e na propaganda: coletânea. Curitiba: Cefet-PR; 2004. p. 85-102.

21. Trotta T, Leszczynski SA, Carvalho, MG. A questão de gênero nas propagandas da televisão. In: Carvalho MG, organizador. Relações de gênero e tecnologia. Curitiba: Cefet-PR; 2003. p. 129-150.

22. Sarlo B. Cenas da vida pós-moderna: intelectuais, arte e vídeo-cultura na Argentina. Rio de Janeiro: UFRJ; 1997.

23. Williams R. Marxismo e literatura. Rio de Janeiro: Zahar; 1979.

24. Moraes D. A batalha da mídia: governos progressistas e políticas de comunicação na América Latina e outros ensaios. Rio de Janeiro: Pão e Rosas; 2009. p. 45.

25. EstiloRenner. Dia dos Namorados | Renner [Internet]. 2018 [citado em 2019 fev. 02]. Disponível em: https://www.youtube.com/watch?v=wxEwmSyxAEw.

26. Lojas Riachuelo. Riachuelo - Em 2018 \#SejaVocêSejaFeliz ao lado de quem você ama [Internet]. 2018 [citado em 2019 fev. 02]. Disponível em: https://www.youtube.com/watch?v=5p2nclMZ-UI. 